\title{
Clinical Pharmacy Education in India- An Emerging Trend
}

\author{
R H Mishal ${ }^{1, *}$, H B Mishal ${ }^{2}$
}

${ }^{1}$ Sir. Dr. M. S. Gosavi College of Pharmaceutical Education and Research, Prin. T. A. Kulkarni Vidyanagar, Nashik-422005, Maharashtra, INDIA.

${ }^{2}$ MET's Institute of Pharmacy, Bhujbal Knowledge City, Adgaon, Nashik-422003, Maharashtra, INDIA.

\begin{abstract}
Since the inception of Pharmacy education in 1937 in India, the past few decades have experienced a dramatic change in it. In 1948 the Pharmacy Council of India drafted the nation's first standards for Pharmacy practice. The following 60 years have seen the country becoming self sufficient in Pharmaceutical production. Pharmacy profession has entered Doctors clinics and hospitals as the Clinical Pharmacists in the recent years. Clinical pharmacy has proven itself into a very promising step of patient care and service in the foreign countries. But for India it is yet a new and unexplored discipline of Pharmacy. The clinical pharmacy discipline is now taking roots in India. Some hospitals have recognized the necessity of clinical Pharmacists in their hospital set up and have started to have them in their patient care service programs. This paper intends to bring out the benefits of Clinical Pharmacy Education in Indian Pharmacy Practice.
\end{abstract}

Key words: Clinical Pharmacy, Education, Drug Manufacturing, Pharmacy practice, Patient care.

\section{INTRODUCTION}

Pharmacy services in recent years have grown significantly beyond drug manufacturing and distribution. These revolutionary changes have promoted greater involvement of the pharmacists in patient care activities and drug related decision making process. Clinical pharmacy has evolved as that specialized branch of pharmacy which deals with patient care with special emphasis on drug therapy. It is a newborn discipline that carries a traditional hospital pharmacist from his product oriented approach to a healthier patient oriented approach. To promote rational drug use and reduce the risk and cost factors associated with multifarious drug therapy expert advice and consultation is needed. Available drug literature is abundant and the society now needs a qualified pharmacist for effective selection, evaluation and utilization of drug literature and communication of existing drug information for use by health professionals. The establishment of clinical pharmacy services would support the rational therapeutic use of drugs as they are directed towards patient care.

\section{DISCUSSION}

At present there are 14 universities in India offering post graduate (M. Pharm) programs in Clinical Pharmacy. Such initiative has also been taken by North Maharashtra University, Jalgaon. This postgraduate program is designed to prepare the pharmacist for an expanded role as a provider of direct patient care. The Union Ministry of Health and Pharmacy Council of India has also introduced a six year Doctor of Pharmacy (Pharm D) course. This course provides intensive training in Pharmacy practice and clinical pharmacy services. According to the recent updated list available on the website of the Pharmacy Council of India, there are about 233 Institutes in India in various states offering this Doctor program. With the advent of such post graduate program in clinical pharmacy the entire
DOI: 10.5530/ijopp.11.3.26

Address for correspondence: R H Mishal,

Sir. Dr. M. S. Gosavi College of Pharmaceutical Education and Research, Prin. T. A. Kulkarni Vidyanagar, Nashik-422005, Maharashtra, INDIA. Phone no: +918552002823 Email Id: mishalrashmi@gmail. com

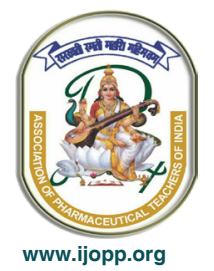


picture of pharmacy profession experienced a dramatic change. These changes saw the pharmacy departments of hospitals initiate patient counseling services with pharmacists serving as the main providers. This marked the beginning of documentation services in the form of medication information and calendars. Apart from this the clinical pharmacy department also provides analytical services. In cases of poisoning, laboratory tests are performed to identify the substance involved. Information on toxicity and appropriate management of the patients are provided by the drug information center. Thus the clinical pharmacist is an expert in the therapeutic use of medications which indicates that the clinical pharmacist is recognized as providing a unique set of knowledge and skills to the health care system and is therefore qualified to assume the role of drug therapy expert. This states that the clinical pharmacist is a primary source of scientifically valid information and advice on the best use of medications.

\section{Role of clinical pharmacists}

A clinical pharmacist usually provides patient care in cooperation with patients, prescribers, and other members of an inter professional health care team that may impact therapeutic outcomes. He promotes health improvement, wellness, and disease prevention in co-operation with patients, communities, at-risk population, and other members of an inter professional team of health care providers. He further demonstrates skills in monitoring of the National Health Programmes and schemes oriented to provide preventive and promotive health care services to the community. A Clinical Pharmacist develops leadership qualities to function effectively as a member of the health care team organized to deliver the health and family welfare services in existing socioeconomic, political and cultural environment. Finally his important role is to communicate effectively with patients and the community.

\section{Scope of Clinical Pharmacy Practice in India}

Pharmacists practicing clinical pharmacy in hospitals may obtain medication histories, counsel patients, review treatment regimens, monitor drug therapy, supply drug information, report ADRs, conduct drug-use evaluations, prepare monographs for formulary consideration, and provide poison control services. Many of the advances in clinical pharmacy in India were initiated in hospitalsparticularly teaching hospitals - just as in many other countries. Clinical pharmacy practice is not well established in the community setting in India, because most pharmacists practicing there have only minimum qualifications, principally only a two-year program leading to a diploma degree in pharmacy. But now people are beginning to recognize the exciting opportunities available in patient counseling and disease management in the community setting and are more likely to set higher educational goals for themselves. Clinical trial coordination, medical information and education, and medical writing are all areas for which clinical pharmacists are suited to work in the pharmaceutical industry. Medical writing and education in the area of marketing allow clinical pharmacists to apply their background in drug information and literature evaluation.

\section{CONCLUSION}

Clinical pharmacy education programs have established their roots in India. Although the evolution of clinical pharmacy education and practice in India is encouraging, it is a great challenge posed to serve such a large, uneducated, exploding population. The Pharmacy council of India has now included pharmacy practice topics in the diploma level and bachelor program. Consistency of both the educational program and the practice environment must be achieved to ensure a high quality of graduates and high standards for pharmacy departments. Individual pharmacists, academic leaders, and hospital administrators must all work together to provide adequate information technology, equipment, drug information resources, and sites for training and research. Yet much work is needed to be done in this stream to expand and improve these programs to bring the benefits of clinical pharmacy practice to the great use of Indian society. For clinical pharmacy to survive and grow in India it must gain acceptance by the medical profession and the community as a whole; the outcome of this challenge rests with today's pharmacy students and teachers.

\section{ACKNOWLEDGEMENT}

The authors wish to acknowledge Principal, MET's Institute of Pharmacy, Adgaon \& Principal, Sir Dr. M. S. Gosavi College of Pharmaceutical Education \& Research, Nashik for their valued support \& co-operation.

\section{CONFLICT OF INTEREST}

The authors declare no conflict of interest.

\section{ABBREVIATIONS}

ADR: Adverse Drug Reaction. 


\section{SUMMARY}

Although the evolution of clinical pharmacy education and practice in India is encouraging, it is a great challenge posed to serve such a large, uneducated, exploding population. For clinical pharmacy to survive and grow in India it must gain acceptance by the medical profession and the community as a whole; the outcome of this challenge rests with today's pharmacy students and teachers.

\section{REFERENCES}

1. Paradkar AR, Chunawala SA. A Textbook of Hospital and Clinical Pharmacy. $30^{\text {th }}$ edition. Nirali Prakashan India. 2011;16.1-16.

2. Tipnis HP, Bajaj. Clinical Pharmacy. First edition. Career publications India. 2003;1-7.

3. Lal LS, Rao PG. Clinical Pharmacy Education in India. American Journal of Health System Pharmacy. 2005;62(14):1510-1.

4. Patel R. Present and Future of Pharmaceutical Education and Pharmacy Profession in India. International Journal of Pharmacy Teaching and Practices. 2012;3(4);384-6.

5. Anonymous. The definition of Clinical Pharmacy. Pharmacotherapy 2008;28(6):816-7. 